University of Nebraska - Lincoln

DigitalCommons@University of Nebraska - Lincoln

Sociology Department, Faculty Publications

Sociology, Department of

2006

\title{
A Longitudinal Study of the Effects of Early Abuse on Later Victimization Among High-Risk Adolescents
}

Kimberly A. Tyler

University of Nebraska-Lincoln, kim@ktresearch.net

Katherine A. Johnson

University of Nebraska-Lincoln

Follow this and additional works at: https://digitalcommons.unl.edu/sociologyfacpub

Part of the Sociology Commons

Tyler, Kimberly A. and Johnson, Katherine A., "A Longitudinal Study of the Effects of Early Abuse on Later Victimization Among High-Risk Adolescents" (2006). Sociology Department, Faculty Publications. 44. https://digitalcommons.unl.edu/sociologyfacpub/44

This Article is brought to you for free and open access by the Sociology, Department of at DigitalCommons@University of Nebraska - Lincoln. It has been accepted for inclusion in Sociology Department, Faculty Publications by an authorized administrator of DigitalCommons@University of Nebraska - Lincoln. 


\title{
A Longitudinal Study of the Effects of Early Abuse on Later Victimization Among High-Risk Adolescents
}

\author{
Kimberly A. Tyler, PhD \\ Katherine A. Johnson, MA \\ University of Nebraska-Lincoln
}

\begin{abstract}
Although previous research on adolescents finds a link between early abuse and later victimization, the majority of this research is cross-sectional and based on samples of currently homeless adolescents. Therefore, factors that predict the likelihood of victimization have not been systematically examined. As such, the current study longitudinally examines the effects of early abuse and poor parenting on victimization via running away, delinquency, and early sexual onset among a sample of over 700 currently housed high-risk adolescents. Results revealed that having experienced sexual and physical abuse, as well as lower levels of parental monitoring and closeness, significantly predicted running away at wave 1 . Adolescents who had run at wave 1 were significantly more likely to run again, more likely to engage in delinquency, and more likely to have had an early sexual onset at wave 3, all of which significantly predicted victimization at wave 4 .
\end{abstract}

Keywords: child maltreatment, running away, victimization, adolescents

pproximately 3.3 million cases of child abuse and neglect were reported in the United States in 2003 and an estimated 906,000 of these reports were sub1 stantiated (U.S. Department of Health and Human Services, 2005). Many children who experience physical and sexual abuse are at risk for experiencing negative developmental outcomes including running away (Tyler, 2002; Tyler, Hoyt, \& Whitbeck, 2000) and revictimization (Beitchman, Zucker, Hood, daCosta, \& Akman, 1991; Desai, Arias, Thompson, \& Basile, 2002; Tyler, Hoyt, Whitbeck, \& Cauce, 2001a). Previous research on adolescents provides support for the link between family conflict and/or abuse and running away (Ek \& Steelman, 1988; Greenblatt \& Robertson, 1993; Miller, Eggertson-Tacon, \& Quigg, 1990; Tyler et al., 2001a; Schweitzer, Hier, \& Terry, 1994; Whitbeck \& Hoyt, 1999) as well as between early abuse and victimization on the street (Simons \& Whitbeck, 1991; Tyler et al., 2001a; Whitbeck, Hoyt, Yoder, Cauce, \& Paradise, 2001). Additionally, early abuse and lower levels of monitoring, attachment, and closeness have been linked to delinquency and early sexual onset (Barnes \& Farrell, 1992; Buzi et al., 2003; Flannery, Williams, \& Vazsonyi, 1999; Laundra, Kiner, \& Bahr, 2002) and delinquency, in turn, is associated with victimization (Baron, 1997; Esbensen \& Huizinga, 1991). Finally, early sexual onset may be associated with an increased risk for victimization given that the earlier adolescents begin having sex, the 
more likely they are to have multiple sexual partners (Durbin et al., 1993), and more sexual partners increases victimization (Logan, Walker, Jordan, \& Leukefeld, 2006). The vast majority of this research, however, is cross-sectional and based on samples of currently homeless youth. Therefore, factors that predict the likelihood that housed adolescents will subsequently run away from home and factors that predict victimization have not been systematically examined using longitudinal data.

Research on nonhomeless populations (cf. Gidycz, Coble, Latham, \& Layman, 1993; Jankowski, Leitenberg, Henning, \& Coffey, 2002; Schaaf \& McCanne, 1998; Smith, White, \& Holland, 2003) also supports the link between childhood abuse and adult victimization. Many of these studies, however, are retrospective, only examine sexual victimization (cf. Gidycz et al., 1993; Jankowski et al., 2002), and often focus on female college students, given their high rates of victimization (i.e., a rate of $54 \%$ found by Koss, Gidycz, \& Wisniewski, 1987). The current study goes beyond previous research in areas of homeless and non-homeless populations by using longitudinal data to examine the effects of early abuse and poor parenting on victimization via running away, delinquency, and early sexual onset within a sample of currently housed high-risk adolescents.

\section{LITERATURE REVIEW}

Research has shown that the majority of runaways have experienced physical abuse (Farber, Kinast, McCoard, \& Falkner, 1984; Tyler \& Cauce, 2002; Whitbeck \& Hoyt, 1999) and between one-third and one-half have experienced sexual abuse, although the prevalence for sexual abuse tends to be higher among females (McCormack, Janus, \& Burgess, 1986; Tyler \& Cauce; Tyler et al., 2001a). Though cross-sectional in nature, numerous studies support the conclusion that many adolescents leave home due to physical and/or sexual abuse (Cauce et al., 1998; Tyler et al., 2001a; Whitbeck \& Hoyt, 1999) or due to familial problems such as conflict and ineffective parenting (e.g., low monitoring) (Whitbeck \& Hoyt, 1999). Comparison studies have revealed higher rates of family conflict and lower rates of parental warmth, care, and support among homeless adolescents compared to their housed counterparts (Dadds, Braddock, Cuers, Elliott, \& Kelly, 1993; Schweitzer et al., 1994). Thus, the decision to leave home is often a combination of family abuse and conflict (Ek \& Steelman, 1988; Greenblatt \& Robertson, 1993; Miller et al., 1990). These early troubled backgrounds (characterized by abuse and/or a lack of quality parental relations) can have cumulative effects leading to higher rates of delinquency and early sexual onset (Barnes \& Farrell, 1992; Buzi et al., 2003; Fergusson, Horwood, \& Lynskey, 1997; Flannery et al., 1999; Laundra et al., 2002; Rebellon \& Van Gundy, 2005). In addition to having cumulative effects, being on the street increases the likelihood that youth will be involved in high-risk behaviors, such as delinquency, which is associated with victimization (Baron, 1997; Esbensen \& Huizinga, 1991; Whitbeck \& Hoyt, 1999). Since prior research on homeless adolescents has found numerous direct and indirect linkages between family troubles and later victimization (Tyler, Hoyt, \& Whitbeck, 2000; Tyler et al., 2001a; Whitbeck \& Hoyt, 1999), we set out to examine similar linkages. First, we expect that early family problems (i.e., child maltreatment and poor parenting) will lead adolescents to run away from home. Additionally, we expect earlier effects to be cumulative. That is, not only will running away and thus spending time on the street lead to participation in high-risk behaviors, but the cumulative effects of their early environment (e.g., sexual abuse) are also likely to lead to early sexual onset, running away numerous times, and delinquency. These experiences (i.e., early family troubles, runaway his- 
tory, delinquency, and early sexual onset) will in turn be linked to victimization. In summary, we expect that family troubles will lead to victimization and that this relationship will be indirect through a process of running away multiple times, engaging in delinquency, and having an early sexual onset.

\section{Theoretical Perspectives Used}

Very few theoretical perspectives have been utilized in the explanation of victimization among homeless and runaway adolescents or college students. One explanation is Finkelhor and Browne's (1985) traumatic sexualization model, which suggests that the trauma of being sexually abused shapes the child's sexuality in ways that are developmentally inappropriate (e.g., promiscuity, sexual aggression) (Gidycz et al., 1993). Similarly, those who have been abused may also learn maladaptive behaviors, have difficulty trusting others (Desai et al., 2002), and experience emotional problems (Beitchman et al., 1991; Morrow \& Sorell, 1989), which in turn may make them more vulnerable to victimization (Tyler, Hoyt, \& Whitbeck, 2000). Another explanation that has been applied is the risk-amplification model (Whitbeck, Hoyt, \& Yoder, 1999), which holds that early abuse and poor parenting indirectly lead to victimization via spending time on the street and participating in high-risk behaviors (Tyler et al., 2001 a; Whitbeck \& Hoyt, 1999). Finally, lifestyle-exposure theory (Hindelang, Gottfredson, \& Garofalo, 1978) and routine activity theory (Cohen \& Felson, 1979) have been applied to understanding victimization among homeless youth (cf. Boney-McCoy \& Finkelhor, 1995; Tyler, Hoyt, Whitbeck, \& Cauce, 2001b). These theories argue that the lifestyles and daily routines of people's everyday lives are related to differential exposure to dangerous places and people, which creates the potential for crime opportunities and therefore for increased victimization. Victimization theories consist of four central concepts: proximity to crime, exposure to crime, target attractiveness, and guardianship. The concurrence of these four constructs increases the likelihood of becoming a victim.

This last theory is particularly relevant to the current study because children who are inadequately supervised or who are not very close to their parents may be more likely to run away from home. Additionally, abused children often suffer from emotional problems (Beitchman et al., 1991; Tyler, 2002) and as a result of these vulnerabilities, may appear as "attractive targets." Further, adolescents who leave abusive situations, run to the streets, and engage in high-risk behaviors are exposed to risky situations and are in greater proximity to crime, thus, their risk for victimization is increased.

\section{High-Risk Adolescents and Victimization}

A fully recursive model was hypothesized to investigate the longitudinal effects of early abuse and poor parenting on victimization via running away, delinquency, and early sexual onset among a sample of currently housed high-risk adolescents (see Figure 1). It was expected that having experienced child sexual and physical abuse and having lower levels of parental monitoring and closeness would predict running away at waves 1 and 3 (Arrows A). This hypothesis was based on that fact that homeless adolescents often report leaving home due to physical and/or sexual abuse (Cauce et al., 1998; Tyler et al., 2001a), ineffective parenting, and family conflict (Dadds et al., 1993; Whitbeck \& Hoyt, 1999).

Child maltreatment and poor parenting are associated with deviant behavior among both homeless youth (Tyler et al., 2001a; Whitbeck \& Hoyt, 1999) and nonhomeless populations (Barnes \& Farrell, 1992; Flannery et al., 1999; Laundra et al., 


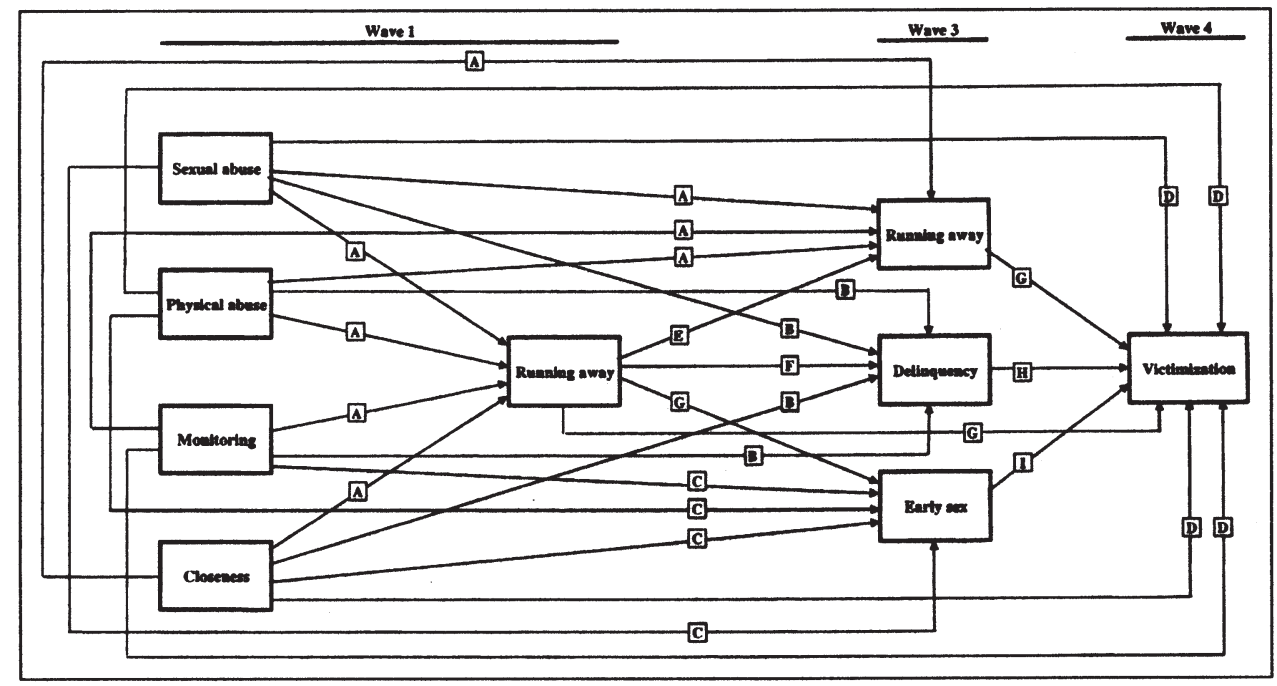

Figure 1. Hypothesized model.

2002; Rebellon \& Van Gundy, 2005; Stouthamer-Loeber, Wei, Homish, \& Loeber, 2002). Additionally, because abused adolescents run away numerous times and spend time on the street (Janus, McCormack, Burgess, \& Hartman, 1987; Tyler et al., 2001a; Whitbeck \& Simons, 1990), they are more likely to be exposed to delinquent youth, thus increasing the likelihood that they will participate in delinquency themselves (Silbert \& Pines, 1982; Whitbeck, Hoyt, \& Ackley, 1997; Whitbeck \& Simons). As such, we hypothesized that child sexual and physical abuse and lower levels of monitoring and closeness would significantly predict delinquent behavior (Arrows B).

Given that child abuse is associated with risky sexual behaviors including early sexual onset among homeless and non-homeless adolescents (Bagley \& Young, 1987; Buzi et al., 2003; Fergusson et al., 1997; Friedrich, Lysne, Sim, \& Shamos, 2004; Tyler, Whitbeck, Hoyt, \& Yoder, 2000), direct effects were hypothesized between child physical and sexual abuse and early sexual onset (Arrows C). Because children who are not closely monitored and who have low levels of closeness and/or support are more likely to participate in risky sexual behavior (French \& Dishion, 2003; Luster \& Small, 1994), direct effects were also expected between lower levels of monitoring and closeness and early sexual onset (Arrows C).

Research finds that the risk of adult physical victimization is double among survivors of child sexual abuse and is increased by 3-4 times among child physical abuse survivors (Desai et al., 2002). Further, abused runaway and homeless adolescents are at risk for victimization on the streets (Bagley \& Young, 1987; Tyler, Hoyt, \& Whitbeck, 2000; Tyler et al., 2001a; Tyler \& Johnson, 2004; Whitbeck et al., 2001) through a process of running away, associating with deviant peers, and participating in delinquent activities (Tyler et al., 2001a). Based on these findings, we hypothesized that physical and sexual abuse would have direct effects on victimization (Arrows D) as well as indirect effects through running away and participating in high-risk behaviors. Additionally, because adolescents with lower levels of parental monitoring and closeness may have more opportunities to participate in risky behaviors (Luster \& 
Small, 1994), and be more apt to come into contact with potential offenders, they are expected to be at greater risk for victimization (Arrows D).

Because research finds that the best predictor of running away is having already done so in the past (Tyler \& Whitbeck, 2004), we hypothesized that running away at wave 1 would predict running away at wave 3 (Arrow E). Additionally, because running away increases the likelihood that adolescents will spend time on the street (Tyler, Hoyt, \& Whitbeck, 2000) and come into contact with other street youth, thus increasing their chances of participating in delinquent behavior (Tyler et al., 2001a), we hypothesized a positive link between running away at wave I and delinquency (Arrow F). Finally, because running away increases the likelihood of coming into contact with potential offenders and increases youths' exposure to other high-risk youth (Tyler et al., 2001b), a direct effect was expected between running away at wave 1 and early sexual onset, running away at wave 1 and victimization, and running away at wave 3 and victimization (Arrows G).

Adolescents involved in deviant activities are at greater risk for assault compared to nondelinquents (Baron, 1997; Esbensen \& Huizinga, 1991; Lauritsen, Sampson, \& Laub, 1991) because engaging in delinquent activities increases individuals' visibility and accessibility to potential offenders (Cohen, Kluegel, \& Land, 1981) and thus increases the risk for victimization. As such, we hypothesized that delinquency would positively predict victimization (Arrow H). Finally, because youth who have an early sexual onset are at greater risk for exposure to multiple sexual partners (Durbin et al., 1993), their odds of coming into contact with a potential offender are increased (Logan et al., 2006); therefore, they are expected to be at greater risk for victimization (Arrow I).

\section{METHOD}

The National Survey of Child and Adolescent Well-Being (NSCAW) is a longitudinal study of youth ranging in age from birth to 14 years old at the time of the initial sampling. The NSCAW study consists of two cohorts and includes a total of 6,228 children and adolescents. The cohort used in these analyses (NSCAW Child Protective Services [CPS]) includes 5,501 adolescents. To be eligible for inclusion in the NSCAW CPS sample, adolescents must have been the subject of a child abuse or neglect investigation conducted by CPS between October 1999 and December 2000. Four states were excluded from the study because "state law required that the first contact of a caregiver whose child was selected for the study be made by CPA agency staff rather than by a NSCAW Field Representative" (Dowd et al., 2004, p. 16). Thus, the NSCAW CPS sample included, "all children in the U.S. who are subjects of child abuse or neglect investigations (or assessments) conducted by CPS and who live in states not requiring agency first contact" (Dowd et al., p. 16).

Data were collected in four waves (baseline, 12 months, 18 months, and 36 months) from a total of four possible reporters. Information was collected from the respondent and the child's teacher (if the child was school aged) at wave 1, 3, and 4 and from the current caregiver (defined as the caregiver most knowledgeable about the child) and the caseworker at all four waves. For the current analyses, only data from children, caregivers, and caseworkers were employed.

\section{Sample}

The current sample included 730 children and adolescents (59.5\% female) who were 11 to 15 years of age at baseline (although the age range was capped at 14 during sam- 
pling, a portion of the youth reached their 15th birthday by the time of the first interview). Approximately $53 \%$ of respondents were non-White and the mean age was 12.76. Over one-third of adolescents (39\%) had experienced physical abuse, with similar rates being reported for males and females (38\% and $39 \%$, respectively). Additionally, $27 \%$ of adolescents had suffered from sexual abuse, with females experiencing significantly higher rates compared to males (36\% vs. $14 \%$, respectively). At wave $1,12 \%$ of respondents had run from home in the previous 6 months and at wave 3 , approximately $10 \%$ had done so. Twelve percent of youth said they had engaged in serious delinquency and 23\% reported an early sexual onset. Finally, 35\% of young people reported being victimized at least once with males experiencing significantly higher rates than females.

\section{Measures}

Childhood sexual abuse was measured in wave 1 when the adolescents were 11-15 years old by assessing caregiver and case worker reports. Case workers were shown a list of 10 types of maltreatment and were asked to determine, based on the child's case report, which best described the most serious type of abuse reported to CPS. This variable was receded into a dichotomous measure of sexual abuse $(0=$ sexual abuse was not the worst type reported to CPS; 1 = sexual abuse was the worst type of abuse reported). Similarly, caregivers were asked four questions that tapped different types of sexual abuse that their child may have experienced, such as being touched by or being forced to touch an adult. These four caregiver items were combined into a dichotomous measure in which no sexual abuse in the child's lifetime was coded as 0 , and any sexual abuse experience in the child's lifetime was coded as 1 . The variables reported by the case worker and caregiver were then combined to form a single sexual abuse measure. Based on both the case worker and the caregiver reports, the variable was coded as 0 if there was no sexual abuse, and coded as 1 if either the case worker, the caregiver, or both reported sexual abuse.

Childhood physical abuse was measured in wave 1 when the adolescents were 11-15 years old. The eight items were adapted from the Parent-Child Conflict Tactics Scale (Straus, Hamby, Finkelhor, Moore, \& Runyan, 1998) in which respondents were asked about experiences they had with their parents or other adults that lived with them. Adolescents who reported ever experiencing severe physical abuse in their lifetimes received a score of 1 . Adolescents who had never experienced any of these forms of abuse received a score of 0 (See Appendix for a list of items).

Parental monitoring was measured in wave 1 when the respondents were 11-15 years old. Five items were adapted from Dishion, Patterson, Stoolmiller, and Skinner (1991) that measured the amount of knowledge the caregiver had about the youth's activities. Two items were reverse coded so that all items were positively oriented (i.e., a higher score indicated more frequent parental monitoring) and a mean scale was created. Response categories ranged from $0=$ never to $4=$ very often. The alpha reliability was .67. The average level of parental monitoring was 3.24, indicating that most youth felt that their caregiver monitored them "pretty often" or "very often." (See Appendix for a list of items.)

Parental closeness in wave 1 was assessed using two items adapted from the National Longitudinal Study of Adolescent Health In-Home questionnaire (Carolina Population Center, University of North Carolina at Chapel Hill, 2002) that asked respondents how close they felt to their primary caregiver, and how much their primary caregiver cared about them. These items were highly correlated $(r=.66)$ and a 
mean scale was created. The responses ranged from $0=$ never, to $4=$ very much, and the resulting scale had a mean of 3.37 indicating that, overall, youth reported being relatively close to their primary caregiver.

Running away was measured at wave 1 (baseline) and wave 3(18 months later) in the current analysis. In both waves, adolescents were asked if they had run away from home in the past 6 months. Responses were coded as $0=$ no and $1=$ yes.

Delinquency was measured in wave 3 by asking respondents questions about their serious delinquent behavior (adapted from Elliott \& Ageton, 1980). Respondents answering yes to at least one item were coded as $1=$ seriously delinquent, while those who answered no to all of the items were coded as $0=$ not seriously delinquent. The alpha reliability for these items was .85 (see Appendix for a list of items).

Early sexual onset was assessed at wave 3 through the use of a composite variable. Youth who reported that they had not had sexual intercourse by the date of the wave 3 interview, or youth who had sexual intercourse for the first time when they were 14 or older, were coded as $0=$ no early sexual onset. Conversely, those who reported having sexual intercourse for the first time at age 13 or younger were coded as $1=$ early sexual onset.

Victimization was measured at wave 4 by asking respondents, "In the past 12 months, how many times has someone physically hurt you on purpose?" Response categories ranged from $0=$ zero times to $4=$ four or more times. In order to separate those who were abused by a caretaker from those who were victimized by someone else, the youth were asked if the person who did this to them was responsible for taking care of them. If the person who hurt them on purpose was a caretaker, the youth was coded as 0 , indicating that they had not been victimized in the previous 12 months because these reports would have been captured in the physical abuse measure.

In terms of our control variables, gender was coded $0=$ male and $1=$ female. Similarly, race was coded $0=$ White and $1=$ non-White. Finally, because some literature (cf., Tyler et al., 2001a; Whitbeck \& Hoyt, 1999) on running away finds that adolescents tend to leave home for the first time at approximately age 13, we controlled for this age difference by dichotomizing this variable into $0=11$ - to 13 -year-olds and $1=$ 14- to 15-year-olds.

\section{RESULTS}

Correlations, means, standard deviations, and ranges for all of the variables are reported in Table 1. A path model was estimated using the weighted least squares (WLS) procedure in LISREL 8 (Jöreskog \& Sörbom, 1993) because many of the variables were dichotomous in this study. The standardized path coefficients, $\beta$, represent the effect of a given predictor variable on the dependent variable after accounting for the remaining relationships in the model. Results for the path analysis in Figure 2 (only significant paths shown), revealed that adolescents who experienced sexual abuse $(\beta=.24)$ and physical abuse $(\beta=.34)$ were more likely to run away at wave I as were those who experienced lower levels of parental monitoring $(\beta=-.08)$ and parental closeness $(\beta=-.16)$. Additionally, males $(\beta=-.06)$ and non-Whites $(\beta=.15)$ were more likely to run at wave 1 . These variables explained $24 \%$ of the variance in running away at time 1.

Adolescents who ran away at wave 1 were more likely to run again 18 months later $(\beta=.29)$, to have engaged in serious delinquency $(\beta=.15)$, and to have had an early sexual onset $(\beta=.15)$. Monitoring $(\beta=-.06)$ and physical abuse $(\beta=.17)$ both had a direct effect on running away at wave 3 . That is, adolescents with lower moni- 


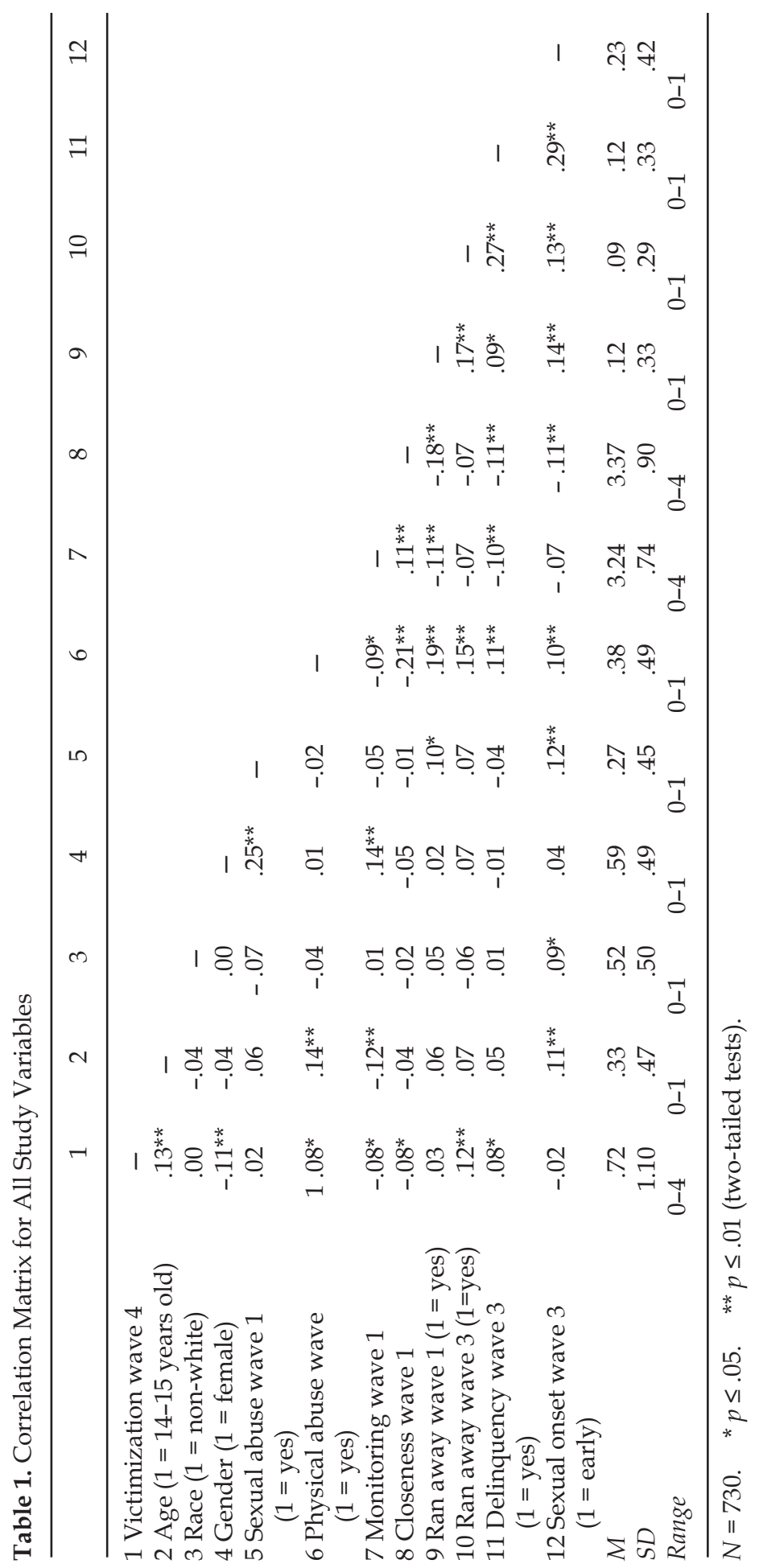




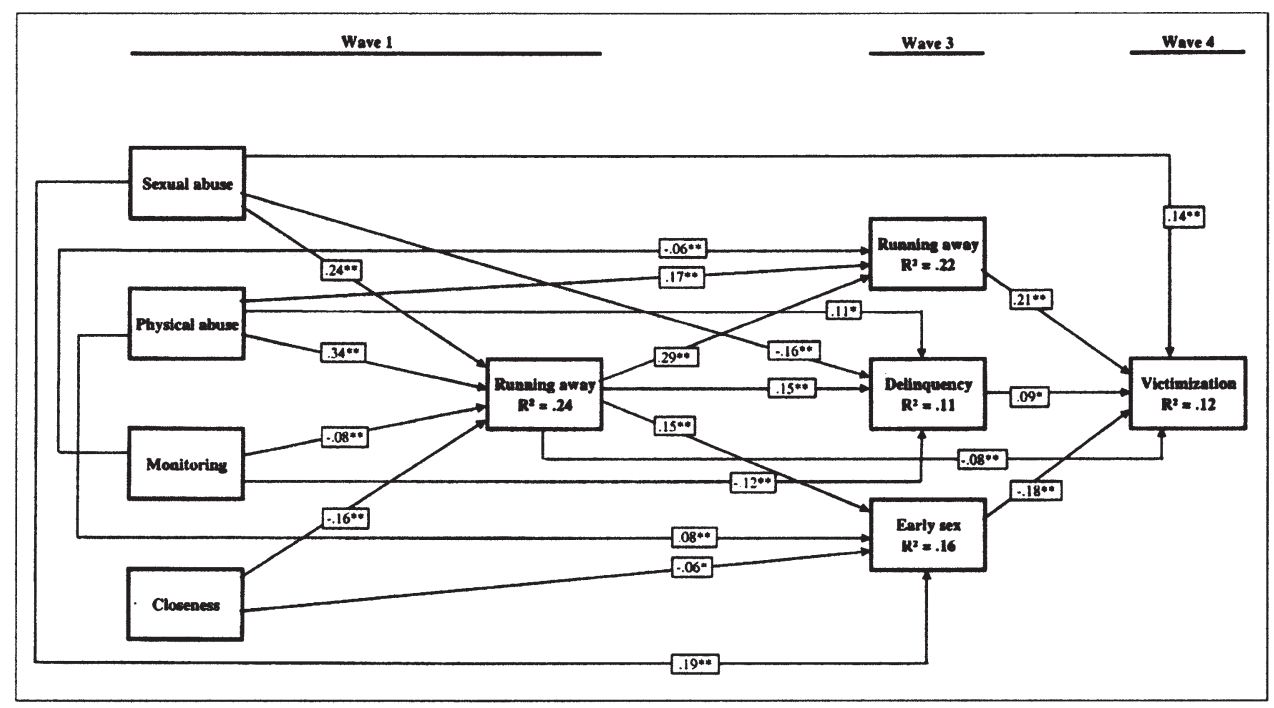

Figure 2. Path model results $(n=730)$.

toring and those who had experienced physical abuse were significantly more likely to run away 18 months later. Additionally, being physically abused $(\beta=.11)$, and having lower levels of monitoring $(\beta=-.12)$ also predicted participating in delinquency. Early sexual abuse was negatively associated with delinquency $(\beta=-.16)$. Having experienced sexual abuse $(\beta=.19)$, physical abuse $(\beta=.08)$, and having a lower level of closeness $(\beta=-.06)$ all had a significant direct effect on early sexual onset. Females were more likely to run away at wave $3(\beta=.15)$, whereas non-Whites were less likely to have run away at wave $3(\beta=-.14)$ but more likely to have had early sex $(\beta=.18)$. Older youth were more likely to have had early sex $(\beta=.14)$. The explained variance for running away at wave 3, delinquency, and early sex were $22 \%, 11 \%$, and $16 \%$, respectively.

In terms of victimization at wave 4 , those who had run away at wave $3(\beta=.21)$ and who reported serious delinquency $(\beta=.09)$ were likely to have experienced higher rates of victimization. Early sexual onset was also associated with victimization $(\beta=$ $-.18)$, although in the opposite direction of what was expected. Two variables from wave 1 also had a direct effect; sexually abused adolescents had higher rates of victimization at wave $4(\beta=.14)$, whereas adolescent runaways were less likely to have been victimized at wave $4(\beta=-.08)$. Males $(\beta=-.21)$ and older youth $(\beta=.13)$ experienced higher rates of victimization. Twelve percent of the variance in victimization was explained in this model.

Because rates of victimization may differ by gender, race, and age, we examined a series of interactions to test the extent to which the effect of each of our controls on victimization was moderated by maltreatment, parenting, and risky behavior. Although all possible combinations of the variables were included as interactions to predict victimization, only those that were significant at the .05 level or below are included in this discussion. This included a total of seven interactions. Because the literature on at-risk youth generally does not hypothesize differences in the effects of maltreatment, parenting, and risky behavior by gender, race, and age, the following interactions should be viewed as exploratory. 


\section{Significant Gender Interactions}

Gender $x$ physical abuse (see Figure 3 ) was statistically significant $(\beta=-.17 ; p=.01$ ), indicating that males who were physically abused were at greater risk for victimization than females. Among those who were not physically abused, gender was less important in the prediction of victimization. Next, the interaction term gender $x$ delinquency (see Figure 4$)(\beta=-.16 ; p=.01)$ indicated that males who participated in delinquency were at greater risk for victimization. The effect of delinquency on victimization for females was minimal. Gender $x$ running away at wave 3 (see Figure 5) was also significant $(\beta=-.21 ; p=.00)$. Although the effect of running away on victimization was minimal for females, males who had run away were more likely to have been victimized.

\section{Significant Race Interactions}

The race $\mathrm{x}$ delinquency interaction $(\beta=.11 ; p=.04)$ indicated that non-Whites who participated in delinquency were at greater risk for victimization, whereas delinquency had little effect on victimization among Whites (see Figure 6).

\section{Significant Age Interactions}

Three age interactions were significant. First, the age $x$ gender term (see Figure 7 ) $(\beta=-.14 ; p=.03)$ indicated that older male youth were more likely to have experienced victimization compared to their younger counterparts. Age had little effect for females in terms of victimization. Next, age $x$ childhood sexual abuse (see Figure 8 ) was significant $(\beta=.21 ; p=.00)$, indicating that among respondents who had not experienced child sexual abuse, rates of later victimization were similar for both age groups. For those who had experienced sexual abuse, however, older respondents had a higher frequency of victimization compared to their younger counterparts. Finally, age x running away at wave 3 (see Figure 9) $(\beta=.13 ; p=.01)$ indicated that older youth who had run away had a higher frequency of victimization compared to their younger counterparts. There was little difference between younger and older respondents who had not run away from home.

The decomposition of the effects of independent variables on the dependent variables (Jöreskog \& Sörbom, 1993) in Table 2 suggests several themes. First, sexual abuse, physical abuse, monitoring, and closeness all had significant indirect effects on running away at wave 3 . Additionally, the effects of sexual abuse and closeness on running away at wave 3 were entirely mediated by running away at wave 1 . Second, sexual abuse, physical abuse, monitoring and closeness all had significant indirect effects on running away, delinquency, and early sexual onset via running away at wave 1. Third, sexual abuse and monitoring had significant indirect effects on victimization via running at waves 1 and 3, through running at wave 1 and delinquency, and via running at wave 1 and early sex. Finally, running away at wave 1 indirectly affected victimization via running away, delinquency, and early sexual onset at wave 3 .

\section{DISCUSSION}

Using multiple waves of data, the current study examines the effects of early abuse and poor parenting on later victimization via running away, delinquency, and early 
Table 2. Decomposition of Effects for Adolescent Victimization

\begin{tabular}{|c|c|c|c|c|c|}
\hline & $\begin{array}{l}\text { Running } \\
\text { at Wave } 1\end{array}$ & $\begin{array}{l}\text { Running } \\
\text { at Wave } 3\end{array}$ & Delinquency & $\begin{array}{c}\text { Early } \\
\text { Sex }\end{array}$ & Victimization \\
\hline \multicolumn{6}{|l|}{ Gender } \\
\hline Direct & $-.06^{*}$ & $.15^{* *}$ & .06 & -.01 & $-.21^{* *}$ \\
\hline Indirect & - & $-.02 *$ & $-.01^{* *}$ & $-.01^{*}$ & $.04^{* *}$ \\
\hline Total & $-.06^{*}$ & $.13^{* *}$ & .05 & -.01 & $-.17^{* *}$ \\
\hline \multicolumn{6}{|l|}{ Race } \\
\hline Direct & $.15^{* *}$ & $-.14^{* *}$ & .00 & $.18^{* *}$ & .09 \\
\hline Indirect & - & $.04^{* *}$ & $.02 * *$ & $.02 * *$ & $-.07^{* *}$ \\
\hline Total & $.15^{* *}$ & $-.10^{*}$ & .02 & $.20^{* *}$ & .02 \\
\hline \multicolumn{6}{|l|}{ Age } \\
\hline Direct & .01 & $.07^{* *}$ & .05 & $.14^{* *}$ & $.13^{* *}$ \\
\hline Indirect & - & .00 & .00 & .00 & -.01 \\
\hline Total & .01 & $.07^{* *}$ & .05 & $.14^{* *}$ & $.13^{* *}$ \\
\hline \multicolumn{6}{|c|}{ Sexual abuse } \\
\hline Direct & $.24^{* *}$ & .00 & $-.16^{\star *}$ & $.19 * *$ & $.14^{\star *}$ \\
\hline Indirect & - & $.07^{* *}$ & $.04^{* *}$ & $.04^{* *}$ & $-.06^{* *}$ \\
\hline Total & $.24^{* *}$ & $.07^{* *}$ & $-.12^{* *}$ & $.22^{* *}$ & $.09^{*}$ \\
\hline \multicolumn{6}{|c|}{ Physical abuse } \\
\hline Direct & $.34^{* *}$ & $.17^{* *}$ & $.11^{*}$ & $.08^{* *}$ & .03 \\
\hline Indirect & - & $.10^{* *}$ & $.05^{* *}$ & $.05^{* *}$ & .02 \\
\hline Total & $.34^{* *}$ & $.27^{* *}$ & $.16^{* *}$ & $.13^{* *}$ & .05 \\
\hline \multicolumn{6}{|l|}{ Monitoring } \\
\hline Direct & $-.08^{* *}$ & $-.06^{* *}$ & $-.12^{* *}$ & -.02 & .01 \\
\hline Indirect & - & $-.02^{* *}$ & $-.01^{* *}$ & $-.01^{* *}$ & $-.02^{*}$ \\
\hline Total & $-.08^{* *}$ & $-.09^{* *}$ & $-.13^{* *}$ & -.03 & -.01 \\
\hline \multicolumn{6}{|l|}{ Closeness } \\
\hline Direct & $-.16^{* *}$ & .02 & -.08 & $-.06^{*}$ & -.09 \\
\hline Indirect & - & $-.05^{* *}$ & $-.02^{* *}$ & $-.02 * *$ & .01 \\
\hline Total & $-.16^{\star *}$ & -.02 & $-.10^{*}$ & $-.09^{* *}$ & -.07 \\
\hline \multicolumn{6}{|c|}{ Running wave 1} \\
\hline Direct & - & $.29^{* *}$ & $.15^{* *}$ & $.15^{* *}$ & $-.08^{* *}$ \\
\hline Indirect & - & - & - & - & \\
\hline \multicolumn{6}{|l|}{$.05^{* *}$} \\
\hline Total & - & $.29^{* *}$ & $.15^{* *}$ & $.15^{* *}$ & -.03 \\
\hline \multicolumn{6}{|c|}{ Running wave 3} \\
\hline Direct & - & - & - & - & $.21^{* *}$ \\
\hline Indirect & - & - & - & - & - \\
\hline Total & - & - & - & - & $.21^{* *}$ \\
\hline \multicolumn{6}{|c|}{ Delinquency } \\
\hline Direct & - & - & - & - & $.09^{*}$ \\
\hline Indirect & - & - & - & - & - \\
\hline Total & - & - & - & - & $.09^{*}$ \\
\hline \multicolumn{6}{|l|}{ Early sex } \\
\hline Direct & - & - & - & - & $-.18^{* *}$ \\
\hline Indirect & - & - & - & - & - \\
\hline Total & - & - & - & - & $-.18^{* *}$ \\
\hline
\end{tabular}

${ }^{*} p \leq .05 . \quad * * p \leq .01$. 
sexual onset among a sample of currently housed high-risk adolescents. Although $27 \%$ of adolescents experienced sexual abuse, females have significantly higher rates compared to males ( $36 \%$ vs. 14\%), which is consistent with previous studies of homeless youth (McCormack et al., 1986; Tyler \& Cauce, 2002; Tyler et al., 2001a). In terms of physical abuse, however, rates reported for males and females are almost identical (38\% vs. 39\%, respectively). These percentages are somewhat lower than those typically found among homeless and runaway youth (cf. Whitbeck \& Hoyt, 1999). Just over one-third of the sample experienced victimization, with males having significantly higher rates compared to females. Overall, early sexual abuse has both direct and indirect effects on wave 4 victimization, whereas the effects of parental monitoring are indirect. Neither physical abuse nor parental closeness significantly predicts victimization.

Consistent with the cross-sectional literature on homeless youth (Cauce et al., 1998; Tyler et al., 2001a; Whitbeck \& Hoyt, 1999), sexual and physical abuse and lower levels of monitoring and closeness all directly predict running away at wave 1 . It is possible that adolescents reach a threshold at which point they can no longer tolerate the abuse and poor parenting and decide to run. As such, running away may be an adaptive response or a short-term coping mechanism (Garbarino, Wilson, \& Garbarino, 1986; Gutierres \& Reich, 1981). Additionally, adolescents with lower levels of monitoring and those who do not feel very close to their caregivers may be more likely to run away because they feel no one cares about them and no one will miss them if they leave.

Physically abused youth are more likely to engage in delinquency, which is consistent with prior studies (Kaufman \& Widom, 1999; Rebellon \& Van Gundy, 2005; Whitbeck et al., 1997; Whitbeck \& Simons, 1990). This effect is both direct and indirect via running away at wave 1 . This is consistent with previous research, which has found that those who experience physical abuse are more likely to be aggressive and antisocial and therefore more likely to participate in delinquent behavior (Whitbeck \& Hoyt, 1999). Additionally, abused adolescents who run away and spend time on the street (Janus et al., 1987; Tyler et al., 2001a) are more likely to be exposed to delinquent youth, thus leading to participation in delinquency (Silbert \& Pines, 1982; Whitbeck et al., 1997; Whitbeck \& Simons).

Lower levels of monitoring have a direct and indirect effect on delinquency. Children who are not closely monitored have greater opportunities to participate in risk behaviors (Luster \& Small, 1994) and are more likely to associate with youth who may get them into trouble. Additionally, lower levels of monitoring increase the likelihood of running away, which, in turn, increases participation in delinquent activities.

Sexual abuse also has a direct and indirect effect on delinquency. In terms of direct effects, contrary to what was expected, having experienced sexual abuse is negatively associated with delinquency. It is possible that some sexually abused adolescents suffer from internalizing symptoms (Beitchman et al., 1991; Morrow \& Sorell, 1989) and are thus less likely to engage in externalizing behavior such as delinquency. Further, those with internalizing symptoms may be more apt to keep to themselves rather than associate with other high-risk youth, and therefore may be less likely to engage in delinquency. In terms of indirect effects, experiencing sexual abuse leads to running away, which in turn increases the risk for delinquent behavior possibly due to the potential of coming into contact with high-risk youth.

Experiencing child sexual and physical abuse predicts an early sexual onset, which is consistent with the general adolescent literature (Buzi et al., 2003; Fergusson et al., 1997). This finding has long-term health implications because having sexual intercourse at earlier ages increases the number of lifetime partners (Durbin et al., 1993), which subsequently may increase the risk for contracting sexually transmitted dis- 
eases (Shafer \& Boyer, 1991). Lower levels of parental closeness also predict early sexual onset as expected. It is possible that youth who are not very close to their caregivers may have less of a stake in conformity, and as such, may not be concerned with what their parents think about their behaviors, including their sexual practices. Additionally, youth may feel that their parents do not care about what they do, and as a result are more likely to engage in risky sexual behaviors.

As expected, child sexual abuse has a direct effect on victimization, which is consistent with the literature on homeless adolescents and high-risk youth (Bagley \& Young, 1987; Tyler, Hoyt, \& Whitbeck, 2000). Because abused adolescents often suffer from emotional problems (Beitchman et al., 1991; Tyler, 2002), they may be viewed as more vulnerable targets and hence more likely to experience victimization. Additionally, sexually abused adolescents may also be at subsequent risk due to their lack of emotional resources and perhaps because they see violence as an expected element of relationships (Desai et al., 2002). Sexual abuse also has an indirect effect on victimization through a process of running away, engaging in delinquency, and early sexual onset. This latter finding is also consistent with studies of homeless youth (cf., Tyler et al., 2001a).

Although early physical abuse leads adolescents to run away, engage in delinquent activities, and have an early sexual onset, it does not have a direct or indirect effect on victimization. Our findings do not concur with Desai and colleagues (2002) (a general population sample) who found that men and women who were physically abused as children were at much higher risk for adult physical victimization. One reason for this discrepancy may be due to the longer time period between measures of physical abuse and physical victimization in Desai and colleagues' study compared to the current study.

Much has been written about child abuse and running away among homeless adolescents; however, very little has focused on the effects of poor parenting. Although lower monitoring is associated with running away (Whitbeck \& Hoyt, 1999), few studies of this population have looked at its effect on victimization. In the current study, monitoring has a significant indirect effect on victimization via all three high-risk behaviors. Lower monitoring not only predicts running away but it also continues to have an impact on the likelihood of victimization 3 years later. Adolescents who experience lower levels of monitoring are more likely to leave home and get into trouble because they have more opportunities to do so when their parents are not checking on their daily activities. Subsequently, they may be more likely to come into contact with potential offenders through participation in delinquent activities, and as a result, are more likely to be victimized.

Adolescents who ran from home at wave 1 are more likely to have run a second time, as expected. This finding is consistent with the literature, which states that previously running away from home is the best predictor of running again (Tyler \& Whitbeck, 2004). Running away at wave 1 also predicts delinquency, early sexual onset, and victimization. It is likely that adolescents who run away are at increased risk of spending time on the street, where they may interact with runaways or street youth. This contact and exposure with high-risk street youth may lead to youths' participation in delinquent activities, which increases their visibility and exposure to potential offenders and hence their risk for victimization (Cohen et al., 1981). Additionally, this increased exposure and proximity to potential offenders may also result in a greater risk for sexual contact at an early age and hence, increased victimization. Finally, although runaway status at wave 1 significantly predicts victimization, the relationship is not in the hypothesized direction. This is an anomaly given that running at wave 3 does predict victimization, and in the hypothesized direction. It is possible that youth 
who run away at age 11 to 15 stay with friends or another safe place rather than on the street, whereas 18 months later, when they are approximately 13 to 17, they may not. It is also possible that younger adolescents run from home for shorter periods of time, thus leading them to experience less victimization. Running at wave 1, however, does have a significant indirect effect on victimization via running away, delinquency, and early sexual onset at wave 3 .

Delinquency predicts victimization in the current study. This is consistent with the literature, which indicates that adolescents involved in delinquency are at greater risk for assault compared to nondelinquents (Baron, 1997; Esbensen \& Huizinga, 1991; Lauritsen et al., 1999). Further, engaging in delinquency increases individuals' visibility and accessibility to potential offenders (Cohen et al., 1981) and thus increases the risk for victimization. Finally, although early sexual onset predicts victimization, the relationship is not in the hypothesized direction. That is, those who had an early sexual onset have lower rates of victimization. One logical explanation for this discrepancy lies in the scope of our outcome variable, which was designed to measure victimization in general rather than physical or sexual victimization specifically. It is likely that if our outcome variable had been specified as sexual victimization only, early sexual onset would have predicted increased victimization, as previous research has found (Fergusson et al., 1997).

Overall, our model reveals that early abuse and poor parenting leads adolescents to initially run away. Subsequently, running from home is related to delinquency, early sexual onset, and running again. These three high-risk behaviors, in turn, predict future victimization. These findings, based on longitudinal data, generally support previous cross-sectional studies that found that runaway and homeless adolescents who experience early sexual abuse are at risk for victimization on the street (Bagley \& Young, 1987; Tyler, Hoyt, \& Whitbeck, 2000; Tyler et al., 2001a).

Our results also reveal that the paths leading to victimization differ significantly by gender, race, and age. Our three significant gender interactions indicate that physical abuse, delinquency, and running away at wave 3 increase the frequency of male victimization while having little effect on female victimization. It is possible that these variables are inherently gendered and work via sex-differentiated processes. Among males for example, the consequence of physical abuse may manifest itself in aggression and antisocial behavior, which leads them to form ties with delinquent youth, which in turn increases their risk for victimization. The effects of delinquency and running away at wave 3 also differ by gender. It is possible that boys and girls engage in different types of delinquency and are exposed to different risk factors when they run away. It is also possible that there are other protective factors for girls that buffer them from the effects of delinquency and running away. The effect of delinquency on victimization is also moderated by race. Our findings indicate that among those who reported engaging in serious delinquency, non-Whites are more likely to be victimized than Whites. It is possible, because of racial segregation, that the circumstances under which youth commit serious delinquency are different among racial and ethnic groups. Delinquency may be a more dangerous endeavor for non-Whites than Whites. Finally, older respondents who experienced sexual abuse and who ran away at wave 3 experience higher rates of victimization. It is possible that the negative outcomes of child sexual abuse that lead to victimization lie dormant until later adolescence. According to the current findings, child sexual abuse leads to increased victimization among older respondents (17-18 at wave 4); however, the same is not true for those who were younger (14-16 in wave 4). It is likely that the developmental tasks inherent in late adolescence are disrupted by the effects of child abuse and lead to frustration and risk-taking behavior that may re- 
sult in victimization. Perhaps those in the younger age range have yet to reach this age-graded threshold. Similarly, those who were older when they ran away from home may have had different experiences from those who were younger when they ran away. It is likely that older adolescents stay away from home for longer periods of time and engage in riskier behaviors than their younger counterparts, and thus are likely to experience more frequent victimization.

It is noteworthy that our study was primarily limited by measurement issues inherent in the use of secondary data sets. For example, our measures of sexual and physical abuse, monitoring, closeness, and running away at wave 1 were all measured at the same point in time. This is not problematic, however, given that respondents were asked to report on their running away behavior during the previous 6 months, whereas the family background variables (e.g., sexual abuse, physical abuse) likely occurred well before this. Additionally, although our victimization measure asked respondents whether someone physically hurt them, we are unable to distinguish between physical and sexual assault. This may also be viewed as a benefit of this study, however, because it allowed adolescents to consider either scenario. Further, because the majority of prior research has focused on sexual victimization, the neutrality of our outcome variable may be viewed as an asset. Another limitation is that we cannot determine how long the respondent was away from home before returning. It is likely that those who stay away for longer periods of time experience greater risk and therefore higher rates of victimization. Additionally, the 3-year time span between our predictor variables and our outcome variable is shorter than many other studies. Further, some of the measures in the current study are retrospective and may be subject to recall bias. Finally, given that we examined variables over four waves and used multiple reporters, it is not surprising that there were missing data. An examination of the respondents with missing data revealed that they were not significantly different from those with no missing data on any variables with the exception of race and delinquency; those who were non-White and nondelinquent were more likely to have missing data than those who were White and delinquent. Given these limitations, the results should be interpreted with caution.

Notwithstanding these concerns, our data also have several strengths that allowed us to address many of the shortcomings in the current literature. First, much research on running away and victimization is based on samples of already homeless youth. The multiple-wave sampling design employed in the NSCAW data allows us to estimate causal ordering and examine the runaway patterns of housed adolescents. This has not previously been done in the homeless literature with these variables. Additionally, our data combined reports from multiple sources. Third, our findings build upon existing data from less representative samples and shed important light on precursors to running away and victimization among a sample of housed, high-risk adolescents. Finally, our findings have several important implications given what the research on the general population has found. That is, youth who have been abused in both childhood and adolescence are at increased risk for victimization as they approach young adulthood (Gidycz et al., 1993; Siegel \& Williams, 2003). Additionally, the combination of sexual and physical abuse in childhood doubles the risk for victimization in college (among women) (Schaaf\& McCanne, 1998). Given that some children in the current study (i.e., 10\%) have experienced both physical and sexual abuse and that some adolescents have also experienced victimization, then at least some of the youth in the current study are at particularly high risk for further victimization as they approach their young adult years.

Our findings are important because knowing that abuse initiated early on may be repeated through different developmental stages signals the need for practitio- 
ners and other professionals to target high-risk groups and to intervene before adolescents initially run from home. Additionally, there is a need to identify problems associated with running away (e.g., early abuse, poor parenting) because if left unchecked, problems may result in repeated running away, which increases the likelihood of spending time on the street, which in turn leads to participation in high-risk behaviors and victimization (McMorris, Tyler, Whitbeck, \& Hoyt, 2002; Tyler, Hoyt, \& Whitbeck, 2000; Tyler \& Johnson, 2004). Finally, identifying precursors is important because childhood difficulties with family as well as running from home are associated with later adult homelessness (Burt, Aron, Lee, \& Valente, 2001).

Future research should continue to employ general population samples that examine precursors to running away and their effect on victimization because research on the general population reveals that abuse in childhood and adolescence is associated with an increased risk for sexual victimization among adults (Gidycz et al., 1993; Siegel \& Williams, 2003). In addition to this, research that is able to follow youth well into young adulthood would be especially useful because it would help us to better understand the long-term effects of abuse and if they are similar for males and females. Additionally, it is important to longitudinally examine the extent to which specific types of abuse have different effects on physical victimization versus sexual victimization. Finally, it is important to not only collect information on the amount of time that adolescents are away from home, but also to find out where they stay, why they return home, and if their relationships with parents/caretakers change or remain the same. Future research that takes into account such measurement and methodological issues will be better able to provide services to these high-risk youth before running away and victimization become a way of life.

\section{REFERENCES}

Bagley, C., \& Young, L. (1987). Juvenile prostitution and child sexual abuse: A controlled study. Canadian Journal of Community Mental Health, 6, 5-26.

Barnes, G. M., \& Farrell, M. P. (1992). Parental support and control as predictors of adolescent drinking, delinquency, and related problem behaviors. Journal of Marriage \& the Family, 54, 763-776.

Baron, S. W. (1997). Risky lifestyles and the link between offending and victimization. Studies on Crime and Crime Prevention, 6, 53-71,

Beitchman, J. H., Zucker, K. J., Hood, J. E., da Costa, G. A., \& Akman, D. (1991). A review of the short-term effects of child sexual abuse. Child Abuse \& Neglect, 15, 537-556.

Boney-McCoy, S., \& Finkelhor, D. (1995). Prior victimization: A risk factor for child sexual abuse and for PTSD-related symptomatology among sexually abused youth. Child Abuse $\& \mathrm{Ne}$ glect, 19, 1401-1421.

Burt, M., Aron, L. Y., Lee, E., \& Valente, J. (2001). Helping America's homeless: Emergency shelter or affordable housing? Washington, DC: The Urban Institute Press.

Buzi, R. S., Tortolero, S. R., Roberts, R. E., Ross, M. W., Addy, R. C., \& Markham, C. M. (2003). The impact of a history of sexual abuse on high-risk sexual behaviors among females attending alternative schools. Adolescence, 38, 595-605.

Carolina Population Center, University of North Carolina at Chapel Hill (2002, November 8). The national longitudinal study of adolescent health. Retrieved May 12, 2003, from http://www. cpc.unc.edu/projects/addhealth/

Cauce, A. M., Paradise, M., Embry, L., Morgan, C. J., Lohr, Y., Theofelis, J., et al. (1998). Homeless youth in Seattle: Youth characteristics, mental health needs, and intensive case management, In K. Kutash, A. Duchnowski, \& M. Epstein (Eds.), Community-based programming for children with serious emotional disturbances: Research and evaluation (pp. 611 -632). Baltimore: Brookes Publishing. 
Cohen, L. E., \& Felson. M. (1979). Social change and crime rate trends: A routine activity approach. American Sociological Review, 44, 588-608.

Cohen. L. E., Kluegel, J. R., \& Land, K. C. (1981). Social inequality and predatory criminal victimization: An exposition and test of a formal theory. American Sociological Review, 46, 505-524.

Dadds, M. R., Braddock, D., Cuers, S.. Elliott, A., \& Kelly, A. (1993). Personal and family distress in homeless adolescents. Community Mental Health Journal, 29, 413-422.

Desai, S., Aria, I., Thompson, M. P., \& Basile, K. C. (2002). Childhood victimization and subsequent adult revictimization assessed in a nationally representative sample of women and men. Violence and Victims, 17, 639-653.

Dishion, T. J., Patterson. G. R., Stoolmiller, M., \& Skinner, M. L. (1991). Family, school, and behavioral antecedents to early adolescent involvement with antisocial peers. Developmental Psychology, 27, 172-180.

Dowd, K., Kinsey, S., Wheeless, S., Thissen, R., Richardson, J., Suresh, R., et al. (2004). National survey of child and adolescent well-being (NSCAW): Combined waves 1-4 data file user's manual general release version. Ithaca, NY: National Data Archive on Child Abuse and Neglect.

Durbin, M., DiClemente, R. J., Siegel, D., Krasnovsky, F., Lazarus. N., \& Camacho, T. (1993). Factors associated with multiple sex partners among junior high school students. Journal of Adolescent Health, 14(3), 202-207.

Ek, C. A., \& Steelman, L. C. (1988). Becoming a runaway: From the accounts of youthful runners. Youth \& Society. 19(3), 334-358.

Elliott, D. S., \& Ageton, S. S. (1980). Reconciling race and class differences in self-reported and official estimates of delinquency. American Sociological Review, 45(1), 95-110.

Esbensen, F. A., \& Huizinga, D. (1991). Juvenile victimization and delinquency. Youth \& Society, 23, 202-228.

Farber. E. D., Kinast, C., McCoard, W. D., \& Falkner, D. (1984). Violence in families of adolescent runaways. Child Abuse \& Neglect, 8, 295-299.

Fergusson, D. M., Norwood, L. J., \& Lynskey, M. T. (1997). Childhood sexual abuse, adolescent sexual behaviors and sexual revictimization. Child Abuse \& Neglect, 21(8), 789-803.

Finkelhor, D., \& Browne, A. (1985). The traumatic impact of child sexual abuse: A conceptualization. Journal of Orthopsychiatry, 55, 530-541.

Flannery, D. J., Williams, L. L., \& Vazsonyi, A. T. (1999). Who are they with and what are they doing? Delinquent behavior, substance abuse, and early adolescents' after-school time. American Journal of Orthopsychiatry, 69(2), 247-253.

French, D.C., \& Dishion, T. J. (2003). Predictors of early initiation of sexual intercourse among high-risk adolescents. Journal of Early Adolescence, 23(3), 295-315.

Friedrich, W. N., Lysne, M., Sim, L., \& Shamos, S. (2004). Assessing sexual behavior in high-risk adolescents with the adolescent clinical sexual behavior inventory (ACSBI). Child Maltreatment: Journal of the American Professional Society on the Abuse of Children, 9, 239-250.

Garbarino, J., Wilson, J., \& Garbarino, A. C. (1986). The adolescent runaway. In J. Garbarino, C. J. Schellenback, \& J. M. Sebes (Eds.), Troubled youth, troubled families: Understanding families at-risk for adolescent maltreatment (pp. 41-54). New York: Aldine de Gruyter.

Gidycz, C. A.. Coble, C. N., Latham, L., \& Layman, M. J. (1993). Sexual assault experience in adulthood and prior victimization experiences. Psychology of Women Quarterly, 17, 151 -168.

Greenblatt, M. \& Robertson, M. J. (1993). Life-styles, adaptive strategies, and sexual behaviors of homeless adolescents. Hospital and Community Psychiatry, 44, 1177-1180.

Gutierres, S. E., \& Reich, J. W. (1981). A developmental perspective on runaway behavior: Its relationship to child abuse. Child Welfare, 60, 89-94.

Hindelang, M. J., Gottfredson, M. R., \& Garofalo, J. (1978). Victims of personal crime: An empirical foundation for a theory of personal victimization. Cambridge, MA: Ballinger.

Jankowski, M. K., Leitenberg, H., Henning, K., \& Coffey, P. (2002). Parental caring as a possible buffer against sexual revictimization in young adult survivors of child sexual abuse. Journal of Traumatic Stress, 15(3), 235-244.

Janus, M., McCormack, A., Burgess, A. W., \& Hartman, C. (1987). Adolescent runaways: Causes and consequences. Lexington, MA: Lexington Books.

Jöreskog , K., \& Sörbom, D. (1993). LISREL 8: User's reference guide. Chicago: Scientific Software. 
Kaufman, J. G., \& Widom, C. P. (1999). Childhood victimization, running away, and delinquency. Journal of Research in Crime and Delinquency, 36, 347-370.

Koss, M. P., Gidycz, C. A., \& Wisniewski, N. (1987). The score of rape: Incidence and prevalence of sexual aggression and victimization in a national sample of higher education students. Journal of Consulting and Clinical Psychology, 55, 162-170.

Laundra, K. H., Kiger, G., \& Bahr, S. J. (2002). A social development model of serious delinquency: Examining gender differences. Journal of Primary Prevention, 22, 389-407.

Lauritsen, J. L., Sampson, R. J., \& Laub, J. H. (1991). The link between offending and victimization among adolescents. Criminology, 29, 265-291.

Logan, T. K., Walker, R., Jordan, C. E., \& Leukefeld, C. G. (2006). Lifestyle factors. In T. K. Logan, R. Walker, C. E. Jordan, \& C. G. Leukefeld (Eds.), Women and victimization: Contributing factors, interventions, and implications (pp. 51 -64). Washington, DC: American Psychological Association.

Luster, T., \& Small. S. (1994). Factors associated with sexual risk-taking behaviors among adolescents. Journal of Marriage and the Family, 56, 622-632.

McCormack, A., Janus, M. D., \& Burgess, A. W. (1986). Runaway youths and sexual victimization: Gender differences in an adolescent runaway population. Child Abuse \& Neglect, 10, 387-395.

McMorris, B. J., Tyler, K. A. Whitbeck, L. B.. \& Hoyt, D. R. (2002). Familial and "on the street" risk factors associated with alcohol use among homeless and runaway adolescents. Journal of Studies on Alcohol, 63, 34-43.

Miller, A. T., Eggertson-Tacon, C., \& Quigg, B. (1990). Patterns of runaway behavior within a larger systems context: The road to empowerment. Adolescence, 25, 271-289.

Morrow, K. B., \& Sorell, G. T. (1989). Factors affecting self-esteem, depression, and negative behaviors in sexually abused female adolescents. Journal of Marriage and the Family, 51, 677-686.

Rebellon, C. J., \& Van Gundy, K. (2005). Can control theory explain the link between parental physical abuse and delinquency? A longitudinal analysis. Journal of Research in Crime and Delinquency, 42, 247-274.

Schaaf, K. K., \& McCanne, T. R. (1998). Relationship of childhood sexual, physical, and combined sexual and physical abuse to adult victimization and posttraumatic stress disorder. Child Abuse \& Neglect, 22(11), 1119-1133.

Schweitzer, R. D., Hier, S. J., \& Terry, D. (1994). Parental bonding, family systems, and environmental predictors of adolescent homelessness. Journal of Emotional and Behavioral Disorders, 2, 39-45.

Shafer, M. A., \& Boyer, C. B. (1991). Psychosocial and behavioral factors associated with risk of sexually transmitted diseases, including human immunodeficiency virus infection, among urban high school students. Journal of Pediatrics, 119, 826-833.

Siegel, J. A. \& Williams, L. M. (2003). Risk factors for sexual victimization of women. Violence Against Women, 9(8), 902-930.

Silbert, M. H., \& Pines, A. M. (1982). Entrance into prostitution. Youth \& Society, 13, 471-500.

Simons, R. L., \& Whitbeck, L. B. (1991). Sexual abuse as a precursor to prostitution and victimization among adolescent and adult homeless women. Journal of Family Issues, 12, 361-379.

Smith, P. H., White, J. W., \& Holland, L. J. (2003). A longitudinal perspective on dating violence among adolescent and college-age women. American Journal of Public Health, 93(7), 1104-1109.

Straus, M., Hamby, S., Finkelhor, D., Moore, D., \& Runyan, D. (1998). Identification of child maltreatment with the parent-child conflict tactics scales: Development and psychometric data for a national sample of American parents. Child Abuse \& Neglect, 22, 249-270.

Stouthamer-Loeber, M., Wei, E. H., Homish, D. L., \& Loeber, R. (2002). Which family and demographic factors are related to both maltreatment and persistent serious juvenile delinquency? Children's Services: Social Policy, Research, \& Practice, 5, 261-272.

Tyler, K. A. (2002). Social and emotional outcomes of childhood sexual abuse: A review of recent research. Aggression and Violent Behavior, 7, 567-589. 
Tyler, K. A., \& Cauce, A. M. (2002). Perpetrators of early physical and sexual abuse among homeless and runaway adolescents. Child Abuse \& Neglect, 26, 1261 -1274.

Tyler, K. A., Hoyt, D. R., \& Whitbeck, L. B. (2000). The effects of early sexual abuse on later sexual victimization among female homeless and runaway adolescents. Journal of Interpersonal Violence, 15, 235-250.

Tyler, K. A., Hoyt, D. R., Whitbeck, L. B., \& Cauce, A. M. (2001a). The impact of childhood sexual abuse on later sexual victimization among runaway youth. Journal of Research on Adolescence, 11, 151-176.

Tyler, K. A., Hoyt, D. R., Whitbeck. L. B., \& Cauce, A. M. (2001b). The effects of a high-risk environment on the sexual victimization of homeless and runaway youth. Violence and Victims, $16,441-455$.

Tyler, K. A., \& Johnson, K. A. (2004). Victims and offenders: Accounts of paybacks, invulnerability, and financial gain among homeless youth. Deviant Behavior, 25, 427-449.

Tyler, K. A., \& Whitbeck, L. B. (2004). Lost childhoods: Risk and resiliency among runaway and homeless adolescents. In P. Allen-Meares \& M. W. Fraser (Eds.), Intervention with children and adolescents: An interdisciplinary perspective (pp. 378-397). Boston: Pearson Education.

Tyler, K. A., Whitbeck, L. B., Hoyt. D. R., \& Yoder. K. A. (2000). Predictors of self-reported sexually transmitted diseases among homeless and runaway adolescents. Journal of Sex Research, 37, 369-377.

U.S. Department of Health and Human Services. (2005). Child maltreatment 2003. Retrieved September 6, 2005, from http://www.acf.dhhs.gov/programs/cb/publications/cm03/chapterthree.htm

Whitbeck L. B., \& Hoyt, D. R. (1999). Nowhere to grow: Homeless and runaway adolescents and their families. New York: Aldine de Gruyter.

Whitbeck, L. B., Hoyt, D. R., \& Ackley, K. A. (1997). Abusive family backgrounds and later victimization among runaway and homeless adolescents. Journal of Research on Adolescence, 7 , 375-392.

Whitbeck, L. B., Hoyt, D. R., \& Yoder. K. A. (1999). A risk-amplification model of victimization and depressive symptoms among runaway and homeless adolescents. American Journal of Community Psychology, 27, 273-296.

Whitbeck, L. B., Hoyt. D. R., Yoder, K. A., Cauce, A. M., \& Paradise, M. (2001). Deviant behavior and victimization among homeless and runaway adolescents. Journal of Interpersonal Violence, 16, 1175-1204.

Whitbeck, L. B., \& Simons, R. L. (1990). Life on the streets: The victimization of runaway and homeless adolescents. Youth \& Society, 22, 108-125.

\section{Acknowledgments}

This document includes data from the National Survey on Child and Adolescent Well-Being, which was developed under contract with the Administration on Children, Youth, and Families, U.S. Department of Health and Human Services (ACYF/DHHS). The data have been provided by the National Data Archive on Child Abuse and Neglect. The information and opinions expressed herein reflect solely the position of the authors. Nothing herein should be construed to indicate the support or endorsement of its content by ACYF/DHHS.

\section{Correspondence}

Dr. Kimberly A. Tyler, University of Nebraska-Lincoln, Department of Sociology, 717 Oldfather Hall, Lincoln, NE 68588-0324. Email: kim@ktresearch.net 


\section{CHILDHOOD PHYSICAL ABUSE}

How many times have your parents or other adults who lived with you ...

1. Hit you with a fist or kicked you hard?

2. Grabbed you around your neck and choked you?

3. Beat you up by hitting you over and over as hard as possible?

4. Burned or scalded you on purpose?

5. Hit you on some other part of the body besides your bottom with something like a belt, hairbrush, a stick or some other hard object?

6 . Threatened you with a knife or gun?

7. Thrown or knocked you down?

8. Slapped you on the face or head or ears?

\section{PARENTAL MONITORING}

1. How often do you leave the house without telling your caregiver or without leaving a note?

2. How often does your caregiver know where you are when you are away from home?

3. How often does your caregiver know who you are with when you are away from home?

4. How often does your caregiver tell you what time to be home?

5. Before going out, how often do you tell your caregiver when you expect to be back?

\section{SERIOUS DELINQUENCY}

In the past 6 months, have you ...

1. Gone into or tried to go into a building to steal something?

2. Stolen or tried to steal things worth between $\$ 50$ and $\$ 100$ ?

3. Knowingly bought, sold, or held stolen goods or tried to do any of these things?

4. Stolen or tried to steal a motor vehicle such as a car or motorcycle?

5. Attacked someone with a weapon or with the idea of seriously hurting or killing them?

6. Used a weapon, force, or strong-arm methods like threats to get money or things from people?

7. Been involved in a gang fight?

8. Been paid for having sexual relations with someone?

9. Had or tried to have sexual relations with someone against their will?

10. Sold hard drugs such as heroin, cocaine, or crack? 